\title{
A Teoria Comportamental de Skinner Aplicada às Informações Contábeis: Um Estudo no Município de Castanhal-PA
}

\author{
Lidiane Nazaré da Silva Dias \\ Professora Assistente \\ Universidade Federal do Pará \\ Av. Augusto Correira, 1 \\ 66.075-970 - Belém-PA \\ lidianedias@ufpa.br \\ Layllana Melo de Oliveira \\ Graduanda em Ciências Contábeis pela UFPA \\ Av. Augusto Correira, 1 \\ 66.075-970 - Belém-PA \\ layllanamelo@hotmail.com \\ Simone de Sousa Britto \\ Graduanda em Ciências Contábeis pela UFPA \\ Av. Augusto Correira, 1 \\ 66.075-970 - Belém-PA \\ simonesbritto@hotmail.com
}

\section{Resumo}

O objetivo desta pesquisa é conhecer a utilização das informações contábeis e a preferência de seus usuários no município de Castanhal, Estado do Pará, verificando os conceitos existentes na Teoria da Contabilidade e no Código de Ética Profissional do Contabilista, em paralelo com a psicologia através da Teoria Comportamental de Skinner. Busca-se no trabalho, através da aplicação de um questionário, coletar dados utilizando-se do método estatístico e seleção aleatória de empresas que apresentavam as seguintes características: faturamento mínimo de $\mathrm{R}$ \$ 2.400.000,00/ano e existência de uma Contabilidade formal no seu cotidiano. Ao final da pesquisa observou-se que $46,67 \%$ dos entrevistados apresentaram pouca satisfação sobre o conteúdo e a forma dos relatórios oferecidos para o processo gerencial, observando dificuldade na relação de parceria entre o usuário e o fornecedor da informação. Os mesmos relatam compreender medianamente as informações prestadas, sendo que, para $60 \%$ dos entrevistados, a apresentação das informações contábeis deve ultrapassar o limite da obrigatoriedade, sendo elaboradas em forma de gráficos, figuras e outras formas que facilitassem a leitura das mesmas, proporcionando, assim, maior compreensão no cotidiano das decisões e, com o reforçamento positivo, maior utilização por parte dos gestores.

Palavras-chave: Teoria Comportamental de Skinner. Contabilidade Aplicada aos Usuários Internos. Teoria da Contabilidade.

\begin{abstract}
The objective of this research is to know the use of accounting information and preference of your users in the city of Castanhal-PA, checking the concepts in Accounting Theory and the Code of Professional Ethics in accounting area, along with psychology through the Skinner

Artigo submetido em 26 de fevereiro de 2009 e aceito em 17 de junho de 2009 pelo Editor José Ricardo Maia de Siqueira, após double blind review.
\end{abstract}


Behavioral Theory. The aim is to work through a questionnaire, collecting data using the statistical method and random selection of firms that have the following characteristics: a minimum receipts of $\mathrm{R} \$ 2.400 .000,00$ per year and the existence of a formal accounting in their operations. At the end, the study showed that $46.67 \%$ of respondents had little satisfaction on the content and format of the reports offered to the management process, noting the difficulty in the partnership between the user and provider of information. They reported moderately understand the information provided, and for $60 \%$ of respondents, the presentation of accounting information should exceed the limit of the obligation and be compiled in the form of graphs, figures and other forms that facilitate the reading of them, providing thus, greater understanding in the daily decisions, and with positive reinforcement, greater use by managers.

Key-words: Skinner Behavioral Theory. Accounting Applied to Internal Users. Accounting Theory.

\section{Introdução}

A Contabilidade sempre foi e continuará sendo propagada como o melhor e mais completo sistema de informações para embasamento das decisões nos âmbitos patrimonial, financeiro e econômico através da interação e integração de grande número de eventos. Este objetivo nasce da necessidade específica de cada usuário, caracterizando, como seu objeto, o patrimônio que é a grande resposta contábil, despertando o desejo de que ela, a Contabilidade, se torne flexível para otimizar os resultados.

Então, para que haja um desenvolvimento nos resultados, o contador tem que buscar atualização profissional e ter um comportamento ético que é indispensável para o sucesso mútuo entre o profissional contábil e a entidade em que atua, sempre cumprindo as descrições do Código de Ética. Desse modo, conhecendo os problemas e fazendo parte da solução dos mesmos, contribuindo, assim, para o aperfeiçoamento e a competitividade, professando a ética da convicção e da responsabilidade pela transparência das administrações públicas e privadas.

Neste contexto, surge a seguinte pergunta: o contador necessita saber qual o tipo de informação que os usuários desejam utilizar?

Diante deste questionamento, a Psicologia direciona para o entendimento e estudo do homem, como forma de melhor interpretar o comportamento humano, pelo fato de cada um ter uma visão distinta dos acontecimentos. Portanto, neste artigo, toma-se como base a abordagem comportamental de Skinner como referência para entender a interação entre o homem, o meio e suas ações. Silva (2009) afirma que, na visão de Skinner, "todo comportamento seria sujeito a mecanismos de controle por meio de contingências de reforço de estímulos capazes de provocar uma determinada ação como resposta". Logo, este artigo tem como objetivo conhecer a utilização das informações contábeis e a preferência de seus usuários no município de Castanhal, Estado do Pará, verificando os conceitos existentes na Teoria da Contabilidade e no Código de Ética Profissional do Contabilista, em paralelo com a Psicologia através da Teoria Comportamental de Skinner a respeito do reforçamento positivo e, conseqüentemente, assertividade.

\section{Objetivos e Usuários da Contabilidade}

De acordo com o Conselho Federal de Contabilidade (CFC), através da Resolução CFC $\mathrm{n}^{\circ}$. 785, de 28.07.95, os usuários da Contabilidade são definidos como sendo as "pessoas físicas ou jurídicas com interesse na Entidade, que se utilizam das informações contábeis desta para seus próprios fins, de forma permanente e transitória”. Por conseguinte, 
Hendriksen e Breda (1982) apud Pinheiro (1997) consideram a necessidade dos usuários da informação contábil como um dos três níveis da Teoria da Contabilidade.

O primeiro problema é a definição do grupo principal de usuários para a utilização de determinadas informações contábeis, onde alguns dizem que deve ser a própria administração e outros acham que devem ser os empregados, ou os clientes, ou o público em geral. $\mathrm{O}$ Financial Accounting Standards Board (1974) apud Hendriksen e Breda (1999) sustenta "que os acionistas, outros investidores e os credores são os principais usuários da Contabilidade". No entanto, Pinheiro (1997) diverge dessa idéia, pois a Contabilidade nasceu dos usuários internos, em um ambiente totalmente prático, acreditando que "a dificuldade identificada sempre recai sobre o usuário da informação contábil (principalmente o interno)". Contudo, fazer uma avaliação do modelo de cada tipo de tomador de decisão seria impraticável dentro da Teoria da Contabilidade.

Tendo isto em vista, o que se espera é que dados reais sejam apurados com fidelidade e transparência em tempo hábil e que constituam base segura na fundamentação de decisões gerenciais. $\mathrm{O}$ que se pode concluir é que existem necessidades e objetivos distintos quanto às informações contábeis que deverão ser apuradas por processos e critérios também diferentes. Vale destacar, que as principais características das informações devem ser sua relevância, a relação do custo-benefício e a flexibilidade perante o usuário e o contexto situacional, conforme destaca Martins (1980) apud Barros (2005):

A informação contábil deve, pois, necessariamente, ser significativa para os problemas decisórios do usuário (relevância) e não custar mais para ser produzida do que o valor esperado de sua utilização (economicidade). Por outro lado, como uma atividade decisória específica determina as necessidades, a relevância está em direta inter-relação (adaptação) com o contexto decisório dessa decisão e com as atitudes e preferências de quem assumirá a decisão.

Por outro lado, segundo Hendriksen e Breda (1999, p. 93), “(...) certos termos contábeis, tais como, lucro líquido e receitas, e mensurações, tais como custo histórico, possuem pouco ou nenhum significado interpretacional no que se refere a fenômenos no mundo real", demonstrando que a grande dificuldade dos usuários é compreender os termos contábeis, criados pelos próprios contadores através de suas normas emitidas pelo Conselho Federal de Contabilidade, o que faz com que alguns usuários não consigam extrair informações relevantes das demonstrações contábeis, dos relatórios, dos atos e fatos extraídos de um exercício em curso, ou ainda de exercícios anteriores. Desse modo, é prudente ressaltar que a qualidade deve ser mais valorizada do que a quantidade das informações.

Ainda conforme Hendriksen e Breda (1999, p.93):

(...) as informações devem ser compreensíveis aos que possuem uma noção razoável dos negócios e das atividades econômicas e estejam dispostos a estudar as informações com diligência razoável.

(...) o objetivo da Contabilidade é medir os recursos possuídos por entidades especificas; refletir os direitos contra essas entidades e os interesses nelas existentes; medir as variações desses recursos, direitos e interesses; atribuir as variações a períodos determináveis; exprimir os dados anteriores em termos monetários como denominador comum.

Numa linha semelhante, Iudícibus (2006) afirma que "o objetivo da Contabilidade é fornecer aos usuários, independentemente de sua natureza, um conjunto básico de informações que, presumivelmente, deveriam atender igualmente bem a todos os tipos de usuários que os ajudarão a tomar decisões".

As entidades buscam uma maior eficiência que lhes permitam atuar num mercado competitivo, objetivando sempre permanência no mercado e crescimento, porém para atingir seus objetivos é necessário interpretar adequadamente os dados técnicos apresentados pela 
Contabilidade através de informações úteis, confiáveis e que, preferencialmente, possua clareza para que, assim, torne-se de máximo proveito para a obtenção de resultados.

\section{Características Qualitativas da Informação}

A Contabilidade gera tecnologia de informação sobre o patrimônio, sendo esta tecnologia componente indispensável à constituição de sistemas de informação (CUNHA, 2005). Obviamente, os dados gerados por este sistema de informação proporcionam conhecimento aos usuários da Contabilidade que irão ser os pilares da otimização da tomada de decisões através da forma e essência útil e relevante das informações prestadas. Portanto, para ocasionar essa informação vantajosa, temos as características qualitativas como sendo as propriedades da informação.

Assim, a natureza do usuário é um fator crucial para a decisão a respeito da informação a ser divulgada, bem como a inteligibilidade ou a compreensão da informação, além da oportunidade da informação (HENDRIKSEN e BREDA, 1999).

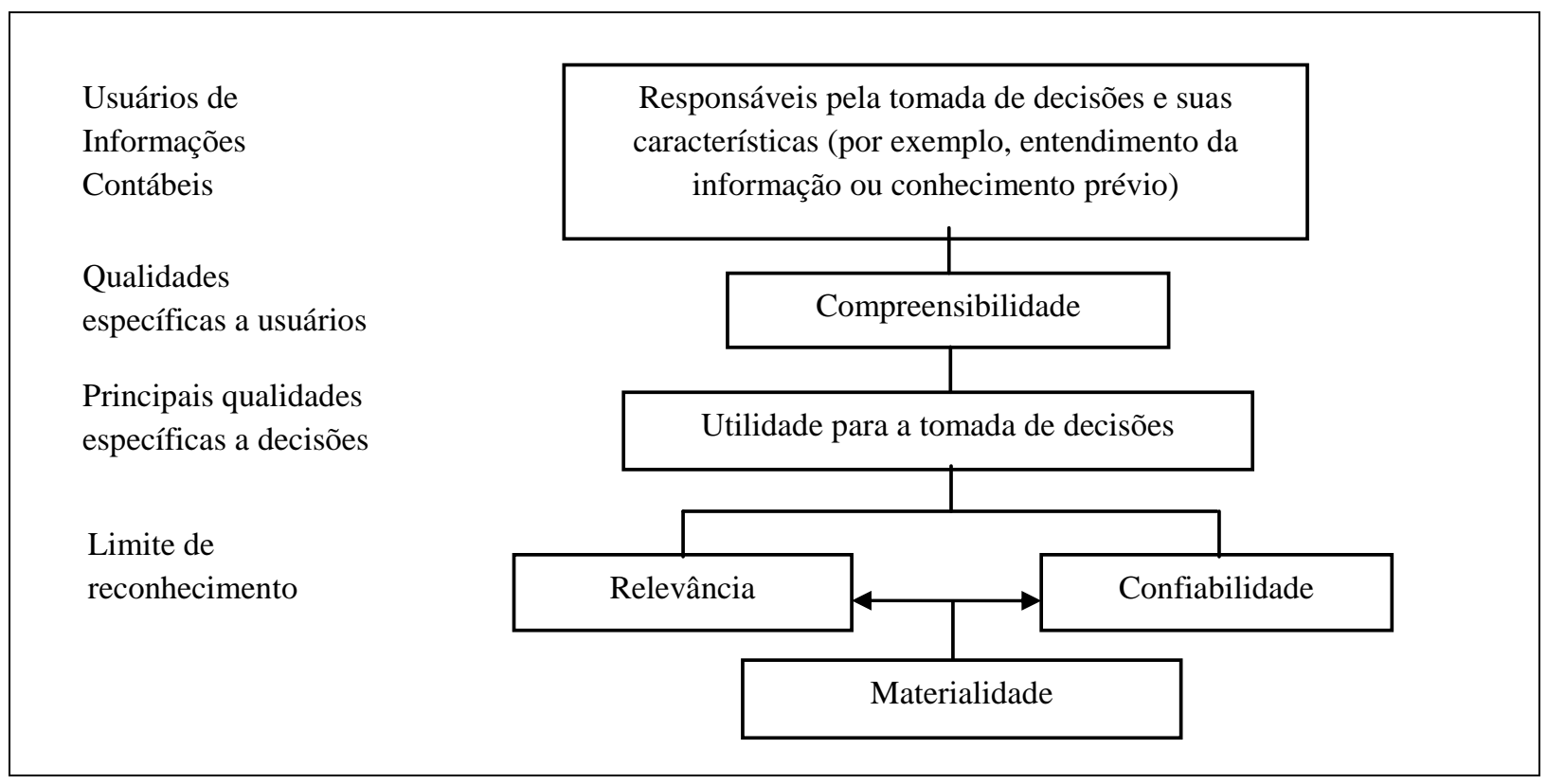

Figura 1: Hierarquia de Qualidade em Contabilidade

Fonte: Adaptado de Hendriksen e Breda (1999, p. 96).

Marion (1997, p. 128) afirma que:

Evidenciação significa tornar evidente, mostrar com clareza, comprovar e, em termos contábeis, está diretamente relacionada com o objetivo principal da Contabilidade que é o de permitir a cada grupo principal de usuários a avaliação econômica e financeira da entidade, num sentido estático, bem como fazer inferências sobre suas tendências futuras.

De forma geral, a informação deve ser relevante ao ponto de traçar metas para que sejam tomadas decisões de forma que ao menos ela tenha sido compreendida por quem a pratica. 
Deste modo, amparado pelo conceito de evidenciação, pode-se entrelaçar a relevância como sendo um requerimento de que a informação seja pertinente ou esteja associada, de maneira útil, às ações que visem facilitar ou atingir os resultados desejados (ASOBAT, 1966 apud HENDRIKSEN e BREDA, 1999, p. 96).

Quadro 1: Relevância

\begin{tabular}{|l|l|}
\hline \multicolumn{2}{|c|}{ RELEVÂNCIA } \\
\hline Relevância para metas & $\begin{array}{l}\text { Alcançada quando a informação permite que as metas dos usuários sejam } \\
\text { atingidas. Determinação difícil quando as metas são subjetivas. }\end{array}$ \\
\hline Relevância semântica & $\begin{array}{l}\text { Alcançada quando o destinatário da informação compreende o significado } \\
\text { pretendido da informação divulgada. }\end{array}$ \\
\hline $\begin{array}{l}\text { Relevância para tomada de } \\
\text { decisões }\end{array}$ & Alcançada quando a informação facilita a tomada de decisões pelos usuários. \\
\hline
\end{tabular}

Fonte: Adaptado de Hendriksen e Breda (1999, p. 97).

À vista disso, para que haja uma grande qualidade na informação prestada ao usuário, destaca-se também confiabilidade que, segundo a Resolução CFC $\mathrm{n}^{\circ}$ 785, de 28.07.95:

(...) é atributo que faz com que o usuário aceite a informação contábil e a utilize como base de decisões, configurando, pois, elemento essencial na relação entre aquele e a própria informação. Logo, a confiabilidade da informação fundamenta-se na veracidade, completeza e pertinência do seu conteúdo.

Por sua vez, verifica-se que a relevância é, pois, todo um complexo de informações, tudo aquilo que pode ajudar no processo da tomada de decisão a fim de permitir boas decisões como forma de sintetizar os dados de maneira que o torne de fácil compreensão aos usuários, caracterizando-se, assim, como uma das responsabilidades do contador que, de forma geral, não deve se deixar mover por atos ilícitos ou até mesmo fabulosos para "perpetuar" o cliente.

\section{Um Questionamento sobre a Ética na Profissão Contábil}

É um aspecto atual saber que a Contabilidade sempre foi e continuará sendo o melhor e mais completo sistema de informações para embasamento das decisões gerenciais. No entanto, a situação-problema é saber se os contadores estão realmente exercendo a "profissão com zelo, diligência e honestidade", conforme descrito no Código de Ética do Contabilista (1996), com o intuito de sempre prestar informações relevantes para a tomada de decisões sobre a estrutura patrimonial e financeira das entidades.

O enlace entre Contabilidade e ética é fundamental para o bom andamento da sociedade e a sobrevivência da própria classe contábil. A profissão deve ser exercida com honestidade e respeito, evitando o uso de método de "ilusionismo financeiro" e sempre ter visão para analisar e interpretar claramente os dados e contas fornecidos.

Epistemologicamente, a origem das palavras "moral" é mores, do latim, e "ética" é ethos, do grego, que querem dizer costume, ou seja, conforme Hendriksen e Breda (1999):

(...) o modo pelo qual as pessoas agem. Hoje em dia, a ética é invariavelmente tratada em termos de como uma pessoa deve comporta-se - e não o faz. Contudo, a origem da palavra nos lembra que também há um aspecto positivo. A ética pode ser um estudo dos costumes que realmente determinam o comportamento das pessoas.

Assim, ao observar o Código de Ética Profissional do Contabilista (1996) em sua essência percebemos que referido profissional deve observar:

(...) a legislação vigente e resguardados os interesses de seus clientes e/ou empregadores, sem prejuízo da dignidade e independência profissionais (...). Guardar sigilo sobre o que souber em razão do exercício profissional lícito, inclusive no âmbito do serviço público, ressalvados os casos previstos em lei ou quando solicitado por autoridades competentes, entre estas os Conselhos Regionais de Contabilidade.

Dias, L. N. S.; Oliveira, L. M.; Britto, S. S. 
Vinculado a uma grande responsabilidade econômica e social, Fortes (2002, p. 117) afirma que o contador deve observar o seu Código de Ética Profissional o qual é "como fonte orientadora da conduta dos profissionais da classe contábil brasileira, que tem por objetivo fixar a forma pela qual se devem conduzir os profissionais da Contabilidade (...)". Ainda neste sentido, Silva e Speroni (1998, p. 78) afirmam que:

(...) a ética profissional tem como premissa maior o relacionamento do profissional com seus clientes e com outros profissionais, levando em conta valores como a dignidade humana, auto-realização e sociabilidade.

Todavia, muitos contabilistas preferem correr riscos praticando atividades ilícitas, ocultar informações, quem sabe até distorcê-las e, conseqüentemente, não prestando informações úteis para os clientes atuais ou em potencial bem como aos outros usuários que visem à tomada racional de decisões. Portanto, o contador tem que ser imparcial, ou seja, suprir com as informações desejadas a cada um dos usuários na medida de suas necessidades, sem objetivar o benefício ou o privilégio de qualquer um em particular (MARTINS, 1997, p. $80)$.

Paralelamente aos fatos, o Código de Ética Profissional do Contabilista deve ser seguido de acordo com os princípios éticos conhecidos e aceito pela sociedade, devendo considerar uma lista de direitos éticos e outra de obrigações éticas, inclusive considerando que as informações geradas pelo contabilista proporcionam subsídios para a tomada de decisões sobre pessoal, investimentos e clientes, ou seja, um complexo de informações à disposição da gestão. Da mesma forma como observamos nessa citação da Martins (1997), cada usuário:

(...) assumirá uma posição e comportamento próprios, dentro daquilo que acredita ser certo e justo para a situação. Desse modo, os objetivos individuais só serão atingidos caso ambas às pessoas, não obstante as posições opostas cheguem a um ponto de entendimento.

Neste contexto, a Ética teoriza, explica e investiga as modificações de cada indivíduo, bem como de toda a sociedade, considerando sempre a diversidade. Mas, toda a inovação de comportamento deve envolver os fundamentos da moral e deve estar entrelaçada à ética, abordando sempre a qualidade das informações prestadas e devendo ser uma alteração moral que a sociedade deve investir para oferecer um referencial útil para a tomada de decisões (MARTINS, 1997, p. 126).

Assim, uma das maiores tarefas dos contadores do futuro é inter-relacionar o pensamento da sociedade e as suas ações, como forma de utilizar a ética no sentido da justiça, da moral e com o propósito do comportamento do indivíduo como ser integrado ao "todo".

\section{Abordagem Comportamental de Skinner: uma interação da Psicologia com a Contabilidade}

O Enfoque Comportamental à Teoria da Contabilidade tem estimulado uma busca de objetivos fundamentais para a Contabilidade e de respostas a perguntas como: Quem são os usuários das demonstrações financeiras publicadas? Qual é a natureza da informação específica desejada pelos vários grupos de usuários? Desse modo, as teorias comportamentais procuram medir e avaliar os efeitos econômicos, psicológicos e sociológicos de procedimentos contábeis (HENDRIKSEN e BREDA, 1999, p. 27).

É neste sentido que a Teoria Comportamental, proposta por Burrhus Frederic Skinner, dedica-se ao estudo do comportamento do indivíduo e a sua relação com o meio ambiente, visando à compreensão do homem como agente transformador e transformado pelo ambiente, demonstrando as associações estabelecidas durante sua vida (meio) e respostas (manifestações comportamentais). 
Diante das mutações vividas, o indivíduo assume determinados comportamentos, podendo estes serem descritos como uma contingência tríplice composta de antecedentesrespostas-conseqüências. Skinner (1999, p. 55) afirma que:

(...) o comportamento humano é o produto conjunto das contingências de sobrevivência responsáveis pela seleção natural das espécies e das contingências de reforçamento responsáveis pelos repertórios adquiridos por seus membros, incluindo as contingências especiais mantidas por um ambiente social que evoluiu.

O comportamento é aquilo que se pode observar o organismo fazendo. É a parte do funcionamento, da ação. Para desenvolver o conceito de comportamento, Skinner estudou dois tipos de eventos comportamentais, o primeiro foi o comportamento respondente sendo o reflexo da ação, de interesse involuntário determinado por causa e efeito - condicionamento com pareamento de estímulos - emoções, onde são elucidados pelos estímulos especiais do meio, contudo podem ser provocados por outros estímulos que nada tem a ver com o comportamento devido somente pela associação dos mesmos. O segundo evento comportamental estudado por Skinner foi o condicionamento operante que diverge no sentido da involuntariedade e, em sua essência, é um ato que pode ser alterado na sua força pelas suas conseqüências, ou seja, a sensibilidade do comportamento aos efeitos externos.

O condicionamento operante permite modelar um determinado comportamento pretendido através da administração dos reforços, sendo que a tríplice contingência do comportamento operante ${ }^{1}$ delimita o que é "Estímulo Antecedente" (SA), "Resposta" (R) e "Conseqüência que Segue uma Resposta" (SC), compreendida como: SA sinaliza quando R pode ser emitida obtendo determinada consequiência (SC), esta consequiência pode fortalecer, inibir ou extinguir um determinado comportamento (ALENCAR, 2006).

Desse modo, a conseqüência que pode fortalecer o comportamento pode ser explicada pelo Reforçamento Positivo que ocorre no âmbito contábil quando, a partir de uma otimização de uma decisão por parte do tomador orientado por uma boa informação do contador, fortalece a probabilidade das decisões serem bem sucedidas, de forma que o tomador valorize o profissional contábil e suas orientações, "um reforçador positivo fortalece qualquer comportamento que o produza", conforme Skinner (1995, p. 43).

Skinner designa o modo causal de seleção por consequiências no qual propõe que as causas do comportamento estão nas conseqüências que ele produz. Segundo este modelo, a determinação do comportamento é produto de processos básicos de variação e seleção de maneira semelhante à teoria da seleção natural proposta por Charles Darwin, ou seja, os comportamentos são selecionados a partir do efeito que produzem no mundo. Portanto, depende do indivíduo e do seu entendimento para o ambiente ser mudado.

\section{Tríplice Contingência sobre o Usuário da Contabilidade}

Em pesquisa de Dias e Paulo (2003), foi feito um paralelo entre a Teoria Comportamental de Skinner, os profissionais de Contabilidade (fornecedores de informações) e os usuários internos (receptores das informações), mais especificamente os gestores. Através da Tríplice Contingência Operante é possível estabelecer uma relação funcional do que ocorre no processo de tomada de decisão por parte desses usuários.

$\mathrm{Na}$ figura abaixo, é demonstrado o processo de formulação das decisões quando da possível apreensão nas mãos dos gestores partindo do reforçamento positivo.

\footnotetext{
${ }^{1}$ São os comportamentos específicos de cada indivíduo, relativos à sua história de vida peculiar e particular.
}

Dias, L. N. S.; Oliveira, L. M.; Britto, S. S. 


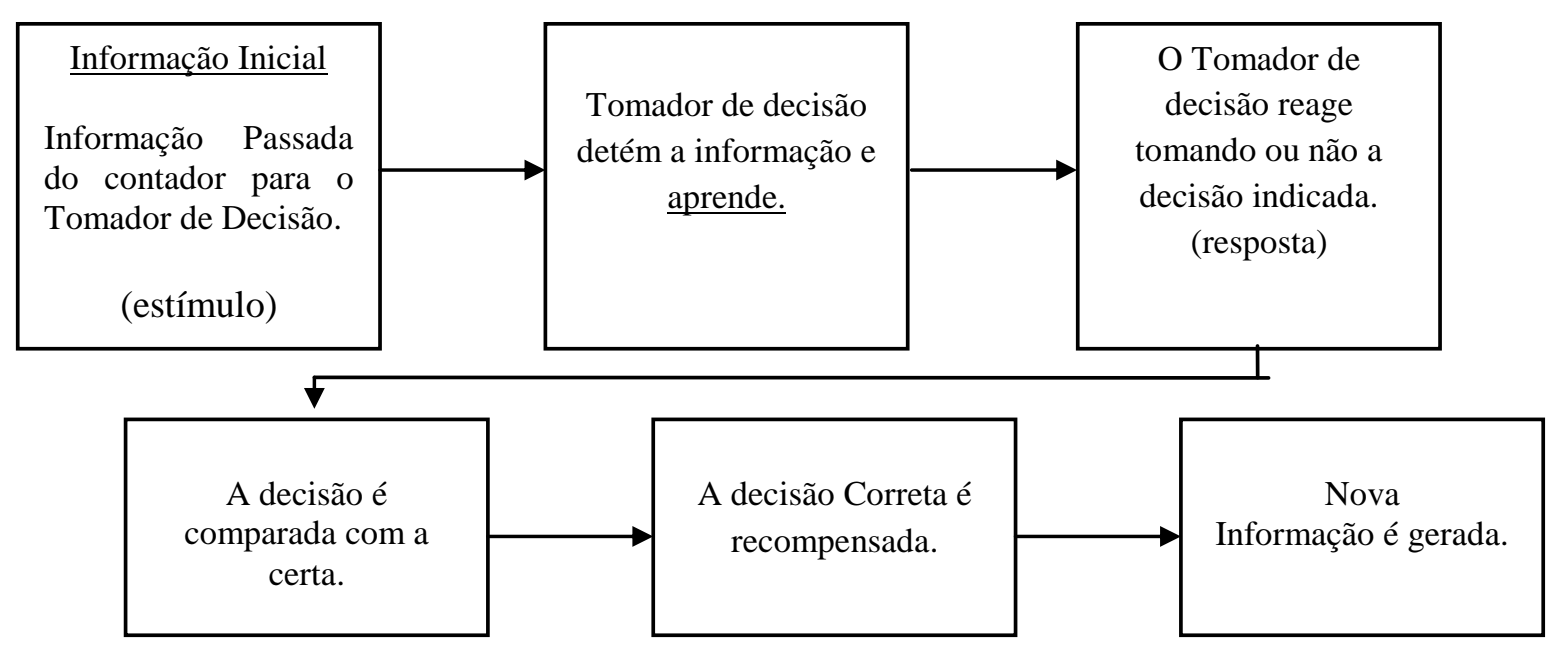

Figura 2: Formulação das Decisões segundo o Reforçamento Positivo

Fonte: Adaptado de Ferreira (1997).

Baseando-se na figura acima, podemos imaginar o transcurso da tomada de decisão utilizando-se as demonstrações contábeis, isto é, se as mesmas forem de fácil compreensão por parte do usuário possibilitarão uma resposta positiva quanto a sua utilização bem como no caso do contador demonstrar confiança e assertividade ao gestor. Logo, na medida em que o gestor utiliza-se das demonstrações contábeis para a tomada de decisão, e a melhor decisão é tomada, gera benefícios à organização e estas demonstrações contábeis terão maior relevância no dia-a-dia da organização, sendo desejada a sua utilização freqüente.

Vale ressaltar, que o reforçamento indica à idéia de aumento de freqüência de respostas desejáveis e a punição, a diminuição da frequiência destas. Deve-se, por isso, reforçar um comportamento quando se quer que ele seja mantido e punir quando se deseja, mesmo que involuntariamente, a sua eliminação. Todavia, enquanto o reforçamento proporciona um comportamento já esperado, a punição não permite tal situação (SKINNER, 1994 apud DIAS e PAULO, 2003).

Em termos conceituais anteriormente citados, conforme Ferreira (1997), "a punição se refere a um desprazer (estímulo) que se faz presente após um determinado comportamento não pretendido", como mostra a figura abaixo: 


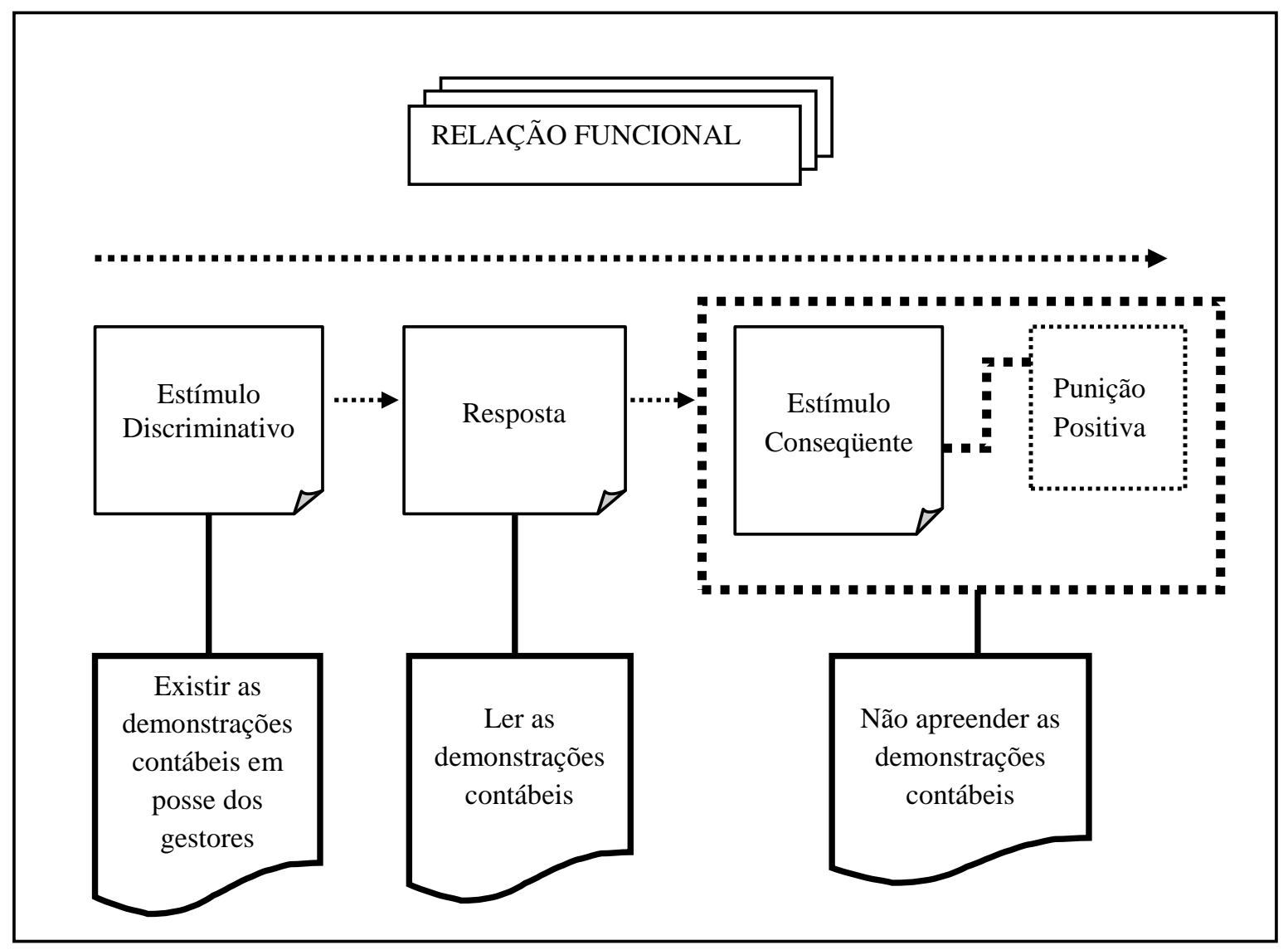

Figura 3: Tríplice Contingência Operante (situação de Punição Positiva)

Fonte: Adaptado de Dias e Paulo (2003).

Diante desta análise, se não houver o entendimento em relação aos relatórios por parte dos tomadores de decisão, a probabilidade de que seja tomada uma decisão equivocada e que provocará problemas gerenciais é maior. Nesse sentido, ocorre que os usuários esperam relatórios úteis que sirvam para beneficiar a continuidade da entidade.

A ênfase, portanto, é de que as informações são veridicamente produzidas, no entanto não se sabe se são relevantes e passíveis de entendimento. Por isso, os conceitos da abordagem comportamental disponibilizam o estímulo (a entrega da informação ao seu usuário), as respostas do mesmo gerando um estímulo conseqüente podendo ser ou não compreensível. Mas, o que se espera é que satisfaça o usuário com intuito deste acertar na sua decisão.

Fornecer informações sobre a posição patrimonial e financeira que sejam úteis a um grande número de usuários, em suas avaliações e tomada de decisões econômicas, é o grande desafio a ser cumprido pelo contador.

\section{Estudo de Campo: Análise Comportamental Aplicada a Gestores de Empresas do Município de Castanhal- PA}

O objetivo do estudo de campo foi conhecer a utilização das informações contábeis e a preferência de seus usuários no município de Castanhal, Estado do Pará, verificando os conceitos existentes na Teoria da Contabilidade e no Código de Ética Profissional do Contabilista, em paralelo com a psicologia através da Teoria Comportamental de Skinner, a respeito do reforçamento positivo e, conseqüentemente, assertividade.

Dias, L. N. S.; Oliveira, L. M.; Britto, S. S. 
Para que este objetivo fosse atingido, foi elaborado um questionário fechado composto de 12 (doze) perguntas objetivas o qual foi encaminhado para usuários dos serviços prestados pelo profissional de Contabilidade de 20 (vinte) diferentes empresas dos segmentos da indústria e do comércio localizadas no município de Castanhal $(75 \mathrm{~km}$ de Belém, capital do Estado do Pará). Tais empresas apresentam uma estrutura modelo equivalentes, ou seja, empresas de bom desempenho econômico-financeiro, exportadoras para outros Estados e estabelecidas na região há vários anos, objetivando, com isto, obter um padrão homogêneo da população pesquisada. Destas 20 empresas, 05 (cinco) não responderam ao questionário.

No questionário elaborado para coletar os dados, foi utilizado o método estatístico e seleção aleatória de empresas que apresentavam as seguintes características: faturamento mínimo de $\mathrm{R}$ \$ 2.400.000,00/ano e existência de uma Contabilidade formal no seu cotidiano.

O Município de Castanhal foi escolhido para ser o centro da pesquisa por se tratar do Município Modelo do Estado do Pará, com cerca de 200 (duzentos) mil habitantes e que abrange, em suas atividades de indústria e comércio, a maior parte da população do pólo nordestino do Estado.

\subsection{Percepção dos Pequenos e Médios Empresários em Relação ao Profissional de Contabilidade face aos Serviços Prestados pelo mesmo}

Os resultados apresentados nos gráficos a seguir foram tabulados em conformidade com as respostas obtidas nos questionários respondidos pelos gestores de pequenas e médias empresas do Município de Castanhal.

Gráfico 1: Utilização das informações contábeis para o processo de tomada de decisão

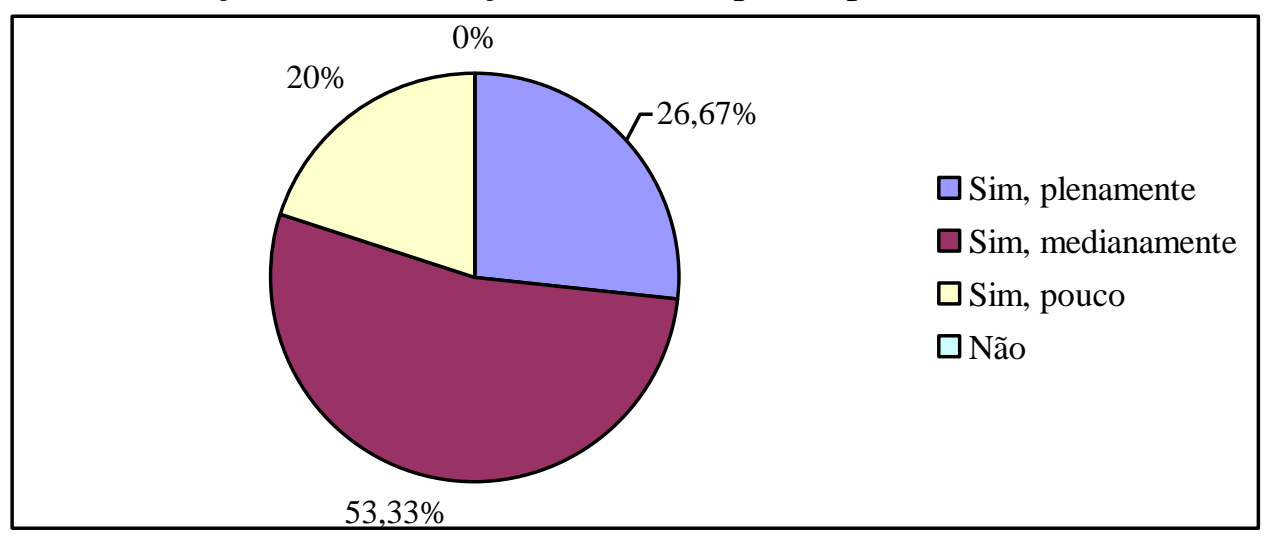

Fonte: Elaborado com os dados da pesquisa. 
Gráfico 2: Principal necessidade da informação contábil

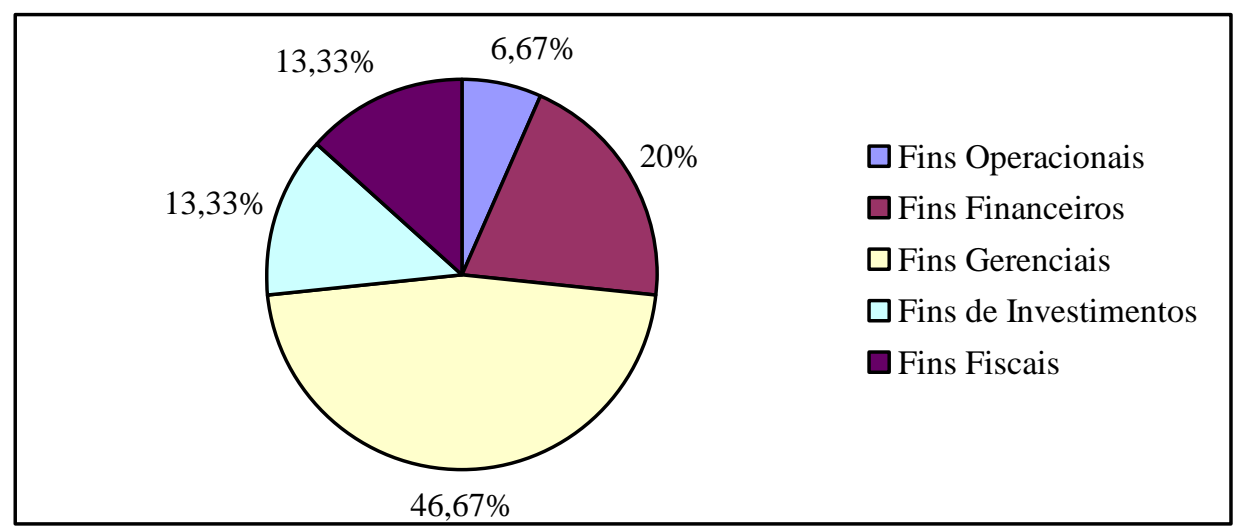

Fonte: Elaborado com os dados da pesquisa.

Gráfico 3: Entendimento das informações contábeis prestadas

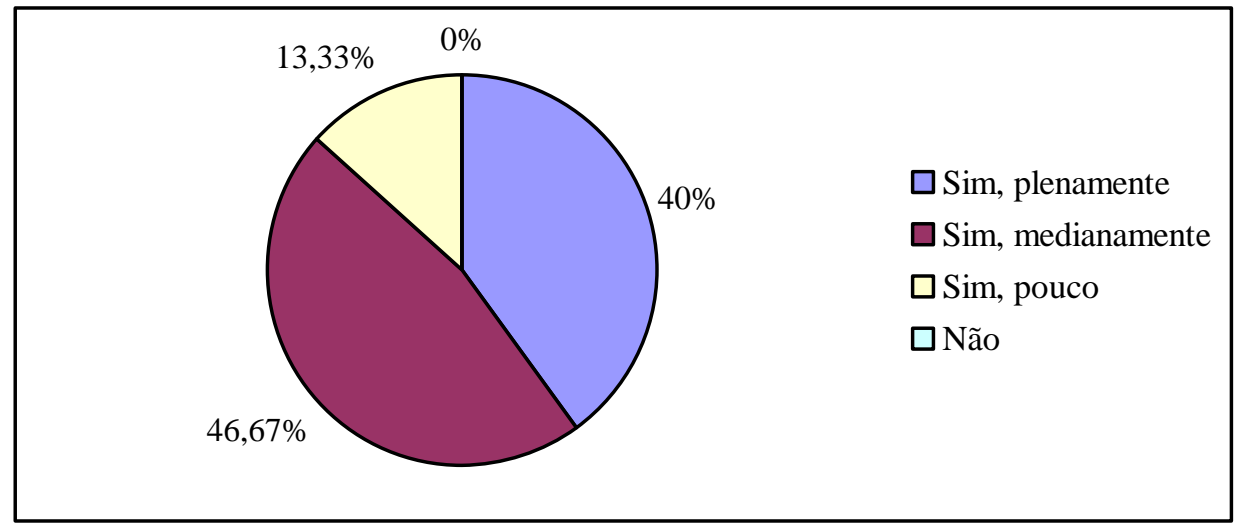

Fonte: Elaborado com os dados da pesquisa.

Gráfico 4: Grau de dificuldade no entendimento das informações contábeis

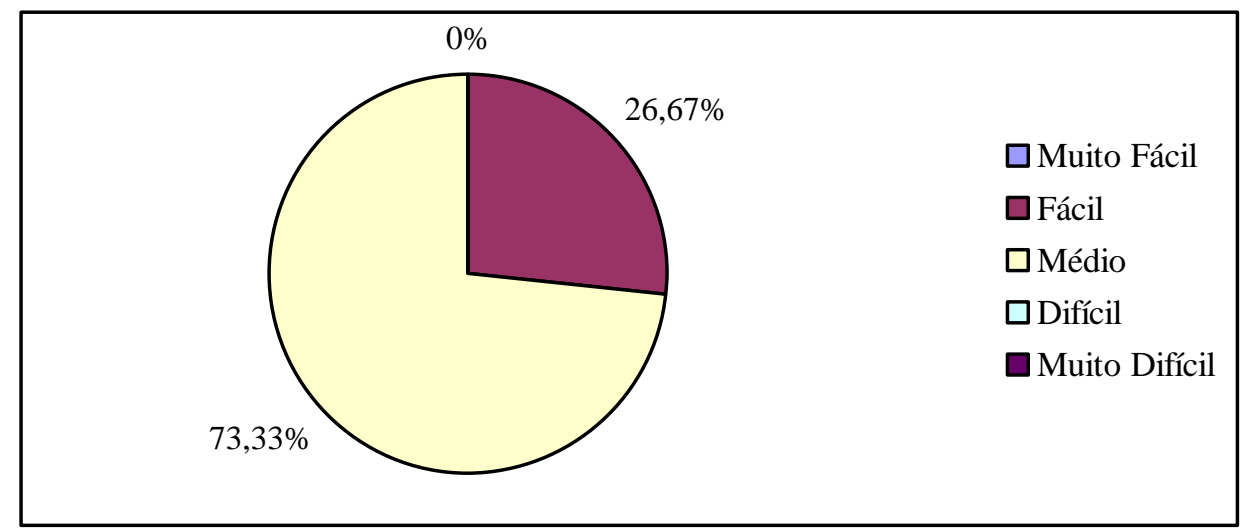

Fonte: Elaborado com os dados da pesquisa. 
Gráfico 5: Percepção de sentimento de parceria por parte do contador da organização

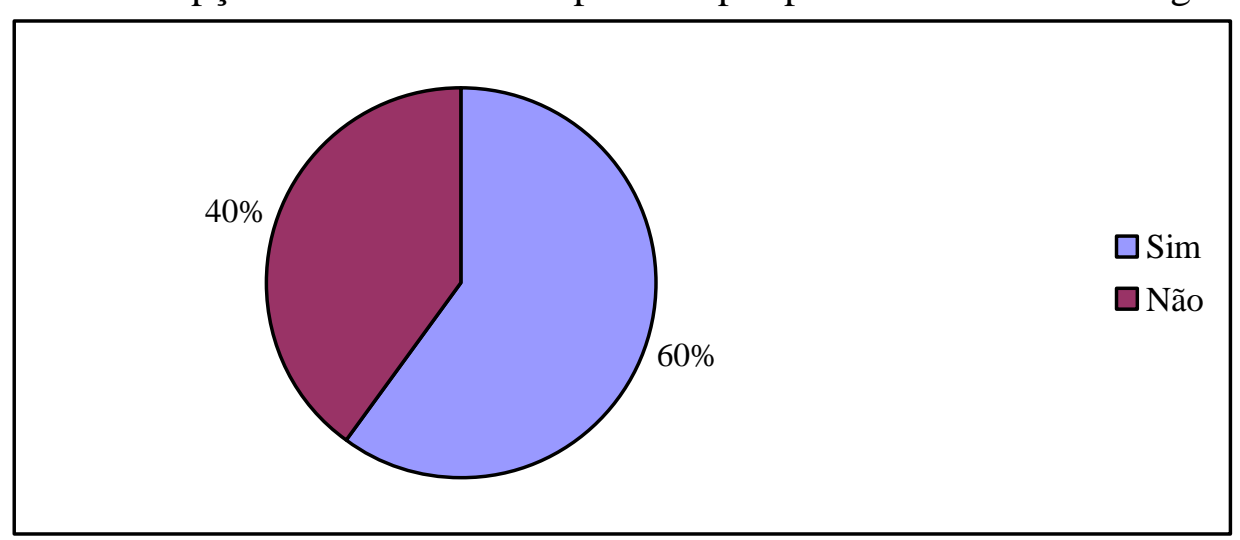

Fonte: Elaborado com os dados da pesquisa.

Gráfico 6: Grau de confiabilidade no Profissional Contábil

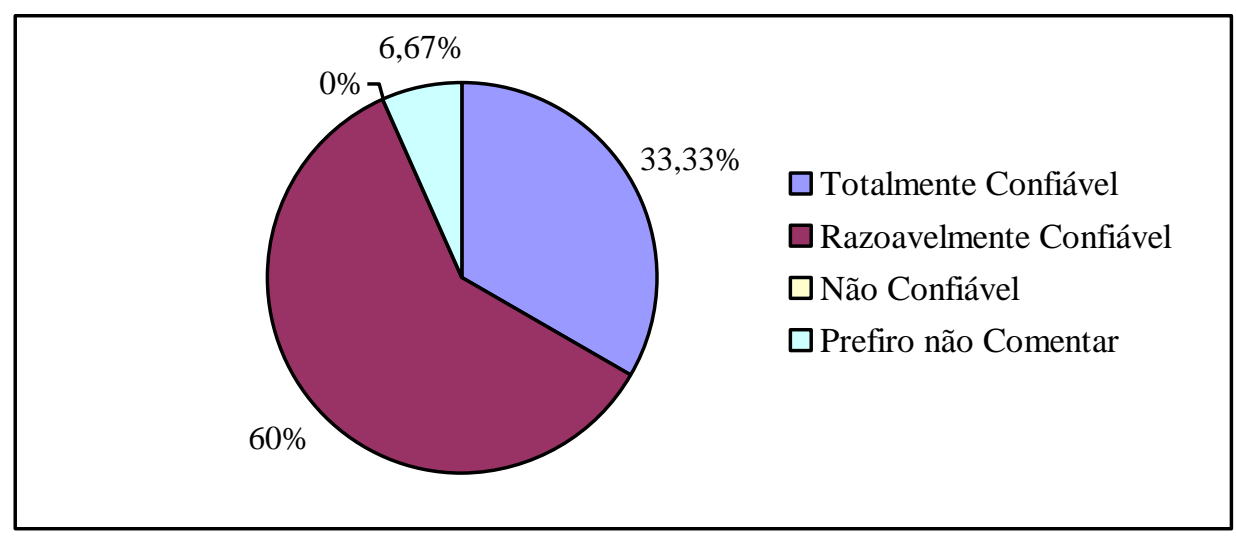

Fonte: Elaborado com os dados da pesquisa.

Gráfico 7: Satisfação com o conteúdo e a forma dos relatórios contábeis apresentados

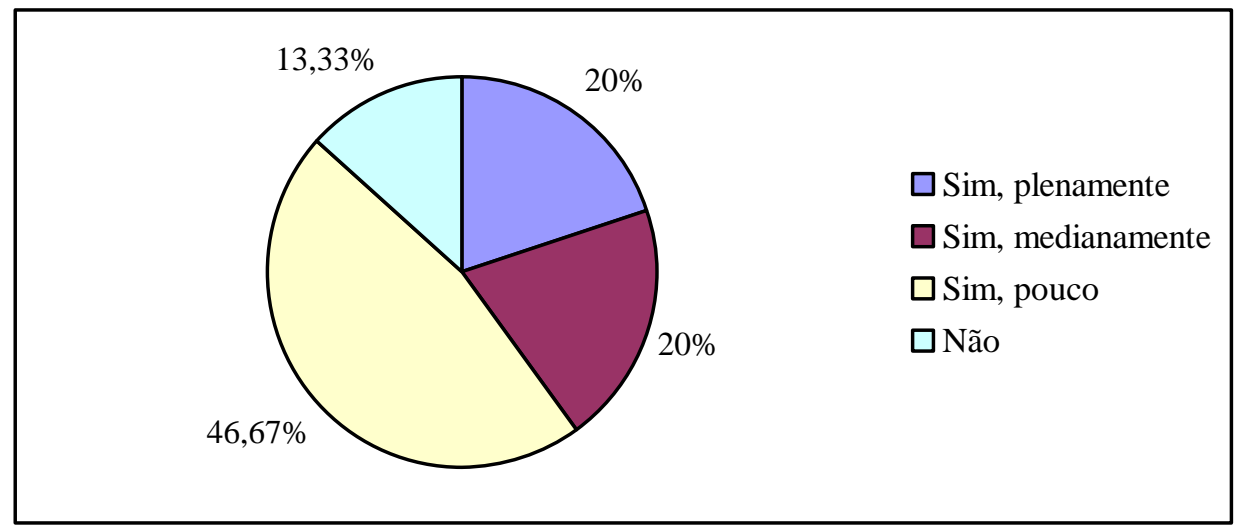

Fonte: Elaborado com os dados da pesquisa. 
Gráfico 8: Preferência sobre a forma como as informações devem ser prestadas

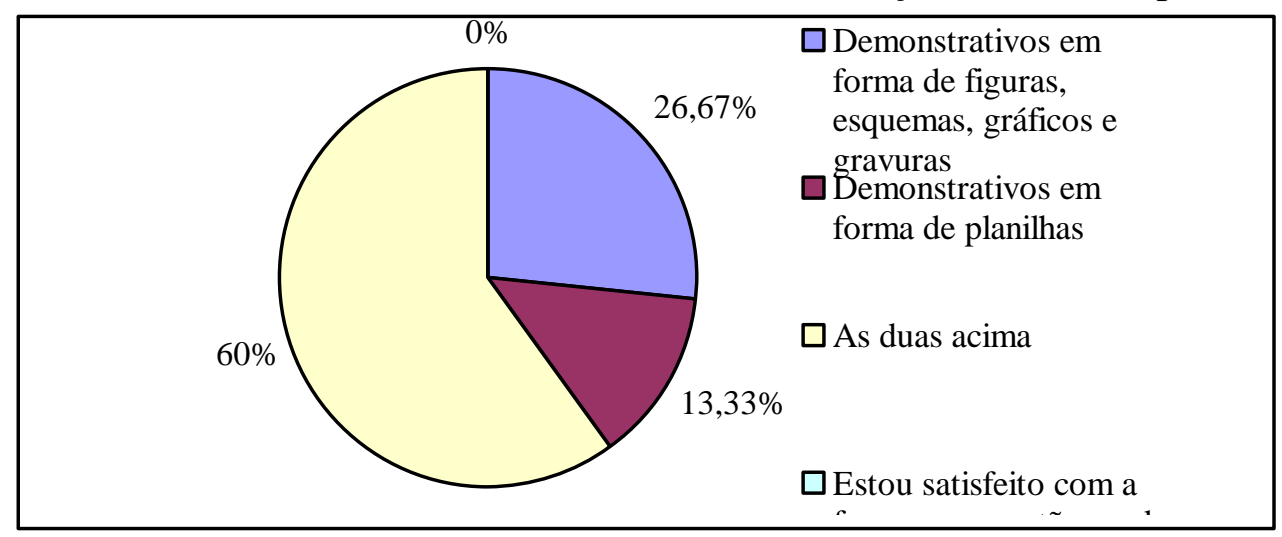

Fonte: Elaborado com os dados da pesquisa.

Gráfico 9: Cumprimento, pelo contador, dos prazos estabelecidos

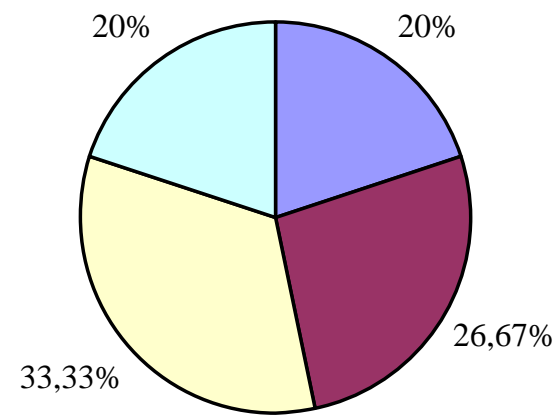

$\square$ Muito bom

$\square$ Bom

$\square$ Regular

$\square$ Ruim

Fonte: Elaborado com os dados da pesquisa.

Gráfico 10: Frequiência que o profissional contábil emite relatórios

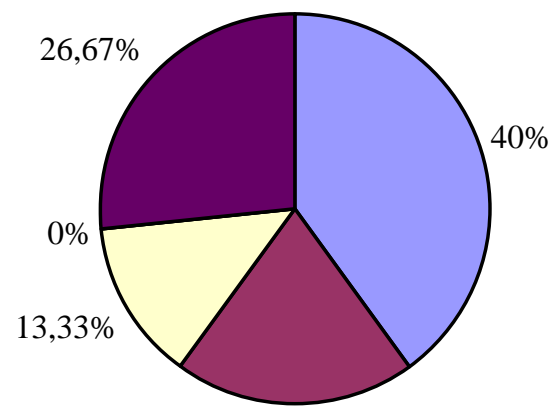

$\square$ Mensalmente

$\square$ Trimestralmente

$\square$ Semestralmente

$\square$ Anualmente

$\square$ Esporadicamente

$20 \%$

Fonte: Elaborado com os dados da pesquisa.

Dias, L. N. S.; Oliveira, L. M.; Britto, S. S. 
Gráfico 11: Informações fornecidas pelos relatórios contábeis para a tomada de decisão

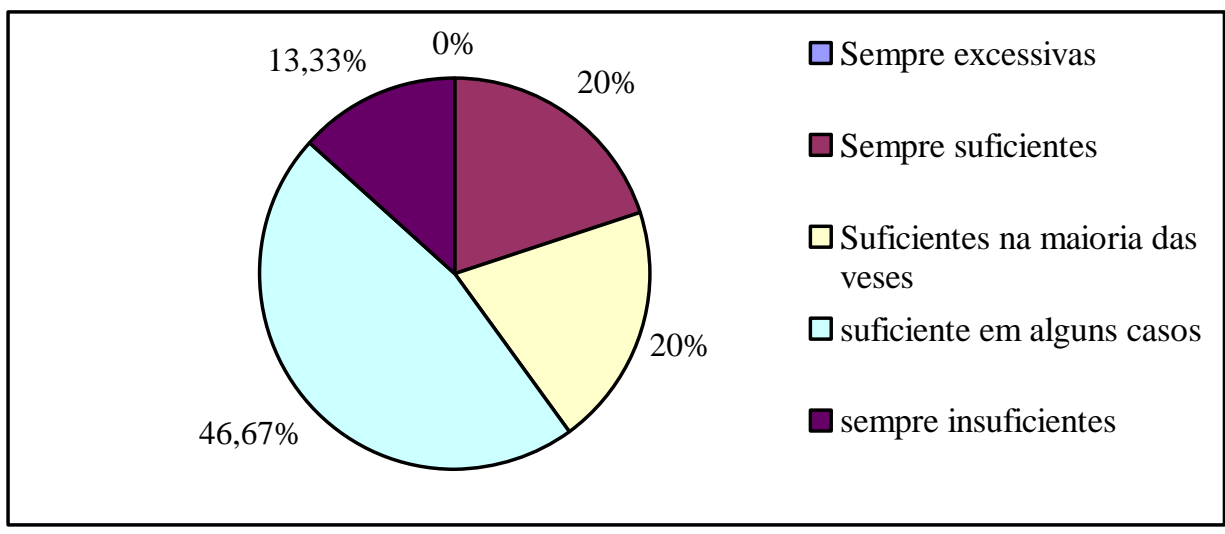

Fonte: Elaborado com os dados da pesquisa.

Gráfico 12: Problemas deparados com maior freqüência ao ler os relatórios contábeis

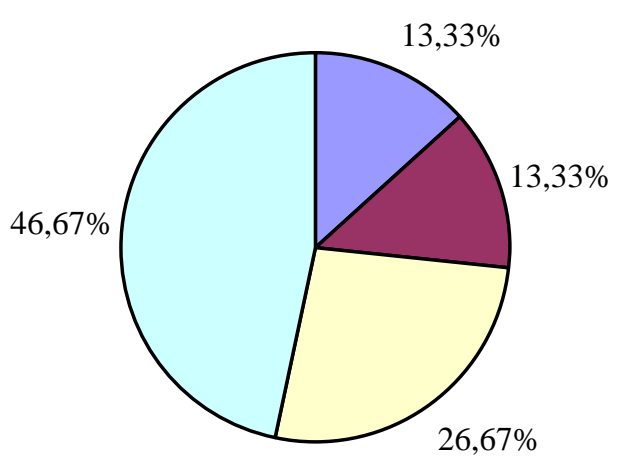

Desconhecimento dos termos contábeis

$\square$ Forma de abordagem dos elementos apresentados

$\square$ Interpretação dos demonstrativos

$\square$ Não tenho dificuldade ao ler os relatórios

Fonte: Elaborado com os dados da pesquisa.

Analisando as informações acima, observa-se, no gráfico 1, que apenas 26,67\% dos gestores das empresas pesquisadas utilizam plenamente as informaçõs contábeis para fins gerenciais como forma de otimizar o processo de tomada de decisão. No entanto, apesar deste baixo percentual de efetiva utilização de referidas informações, quase a metade dos entrevistados afirma que a sua principal necessidade das informações contábeis é para fins gerenciais conforme gráfico 2. Isto pode estar relacionado com o fato de $53,33 \%$ dos entrevistados afirmarem possuir algum tipo de problema na leitura dos relatórios contábeis, seja com o desconhecimento dos termos, problema identificado em 13,33\% dos entrevistados; seja com a forma de abordagem dos elementos apresentados, $13,33 \%$; seja com dificuldade de interpretação dos demonstrativos contábeis, 26,67\% conforme leitura do gráfico 12.

No gráfico 9, verificou-se que mais da metade dos entrevistados (60\%) classifica o cumprimento dos prazos por parte dos contadores como regular ou ruim. Isto pode acontecer, segundo comentário feito por alguns gestores no momento da aplicação do questionário, pelo fato da contabilidade ser terceirizada, não estando o contador permanentemente dentro da organização, o que acaba dificultando a relação de parceria entre o usuário e o fornecedor da informação, conforme resposta tabulada no gráfico 5 , por $40 \%$ dos entrevistados. Outra situação observada que pode dificultar a relação entre usuário e contador é o fato de $60 \%$ dos 
entrevistados precisarem esperar mais de um mês para ter acesso às informações contábeis, conforme gráfico 10, o que dificulta a tomada de decisão e faz com que o primeiro desenvolva outros artifícios que lhe sirvam de base para a tomada de decisão visto não poderem esperar tanto tempo para o recebimento das informações contábeis. Tal situação pode justificar o fato de 60\% (gráfico 6) dos entrevistados sentirem razoável confiança no profissional contábil.

Observa-se que a preocupação dos contadores é referente à abordagem e a normatização dos relatórios, não se preocupando se tais relatórios satisfazem ou não as reais necessidades dos usuários, que muitas das vezes ultrapassam as normas contábeis e obrigações fiscais. Os usuários desejam que as informações sejam apresentadas de forma qualitativa e quantitativa, conforme evidenciado no gráfico 8 , onde $60 \%$ dos entrevistados afirmam querer relatórios com demonstrativos em forma de figuras, esquemas, gráficos, gravuras, planilhas. Neste momento, há uma grande oportunidade de se aplicar o reforçamento positivo para que no ato da repetição dos comportamentos dos gestores no processo de tomada de decisão eles possam compreender as informações e, desta forma, usálas e, consequientemente, usufruir dos benefícios gerados.

\section{Conclusão}

O principal objetivo da Contabilidade é atender satisfatoriamente os seus usuários, apresentando informações úteis e relevantes para melhor tomada das decisões, havendo respeito por todos os campos da informação contábil, sendo que esta é a única forma de procurar desvendar as necessidades de cada usuário minuciosamente.

De acordo com a abordagem comportamental, o contabilista deve assumir de uma vez por todas sua postura gerencial, aperfeiçoando os demonstrativos e utilizando o reforço positivo como aliado na formação da qualidade da decisão pelo fato de usar a afirmação contínua como pressuposto de respostas desejáveis.

Contudo, o profissional contábil tem que apresentar uma postura adequada para dar créditos aos seus serviços e aos seus colegas de profissão, demonstrando padrões éticos e morais até mesmo em seus julgamentos, atendendo, com isto, à Teoria da Contabilidade e ao Código de Ética Profissional do Contabilista.

Nesse sentido, de acordo com a pesquisa realizada com os gestores do Município de Castanhal, 46,67\% dos entrevistados apresentaram pouca satisfação sobre o conteúdo e a forma dos relatórios oferecidos para o processo gerencial. Os mesmos relatam compreender medianamente as informações prestadas, sendo que, para $60 \%$ dos entrevistados, a apresentação das informações contábeis deve ultrapassar o limite da obrigatoriedade, sendo elaboradas em forma de gráficos, figuras e outras formas que facilitassem a leitura das mesmas, proporcionando, assim, maior compreensão e, como reforçamento positivo, maior utilização por parte dos gestores.

A partir do que foi apurado, cabe ao contador ser assertivo através do reforçamento positivo, buscando maior diálogo, buscando conhecer as necessidades dos usuários e buscando atendê-las, o que o tornará um parceiro confiável dos gestores e fará com que seu trabalho seja mais valorizado, oferecendo maior clareza nas informações, inclusive tendo um alto grau de responsabilidade para que os gestores possam sentir a necessidade de utilizar o seu trabalho no cotidiano das decisões.

\section{Referências}

ALENCAR, Eduardo. Como a Análise do Comportamento vem tratando a cultura e as questões sociais?. Momento Behaviorista. 30 nov. 2006. Disponível em:

<http://www.redepsi.com.br/portal>. Acesso em: out. 2008.

Dias, L. N. S.; Oliveira, L. M.; Britto, S. S. 
ASSOCIAÇÃO BRASILEIRA DE NORMAS TÉCNICAS. Trabalhos acadêmicos: NBR 14724. 2. ed.Rio de Janeiro,RJ, 2005.

BARROS, Vaine de Magalhães. O Novo Velho Enfoque da Informação Contábil. Divulgação de Trabalho. São Paulo: R. Cont. Fin. - USP, 2005. Disponível em: <http://www.eac.fea.usp.br>. Acesso em: 07 Set. 2008.

BRASIL. Conselho Federal de Contabilidade. Resolução CFC n ${ }^{\circ} 785$, de 28 de Julho de 1995. Aprova a Norma Brasileira de Contabilidade - NBC T 1. Características da Informação Contábil. Brasília, DF. Disponível em: <http://www.cfc.org.br〉. Acesso em: 07 Set. 2008.

BRASIL. Conselho Federal de Contabilidade. Resolução CFC n ${ }^{\circ}$ 803, de 10 de outubro de 1996. Aprova o Código de Ética Profissional do Contabilista. Brasília, DF. Disponível em: <www.crcrs.org.br>. Acesso em: 17 Jun. 2008.

CUNHA, Patrícia Vasconcelos Boavista. Contabilidade, ética e espaço público. Revista Pensar Contábil: revista do Conselho Regional de Contabilidade do Rio de Janeiro, RJ, v.7, n.29, agosto/outubro 2005.

DIAS, Lidiane Nazaré da Silva; PAULO, Anderson de Oliveira. Os Objetivos e Usuários da Contabilidade sob a Perspectiva da Abordagem Comportamental de Skinner: Um Estudo de Caso. Belém, PA. Universidade Federal do Pará, 2003.

FERREIRA. Instrução programada - Considerações preliminares, Rio Grande do Sul, 1997, Disponível em: <http://penta.ufrgs.br>. Acesso em: 03 nov. 2008.

FORTES. José Carlos. Ética e responsabilidade profissional do contabilista. Fortaleza: Fortes, 2002.

HENDRIKSEN, Eldon; BREDA, Michael F. Van. Teoria da Contabilidade. Tradução da 5. ed. Americana por Antonio Zoratto Sanvicente. São Paulo: Atlas, 1999.

IUDÍCIBUS, Sérgio de. Teoria da Contabilidade. 8. ed. São Paulo: Atlas, 2006.

MARION, José Carlos. Contabilidade Empresarial. 6. ed. São Paulo: Atlas, 1997.

MARTINS, Eliseu. Ética Geral e Profissional em Contabilidade. Fundação Instituto de Pesquisa Contábeis, Atuariais e Financeiras (FIPECAFI) 2. ed. São Paulo: Atlas, 1997.

PINHEIRO, Fábio A. O postulado do usuário: incentivo ao desenvolvimento da Teoria da Contabilidade e do contabilista. Caderno de Estudos, Fipecafi, São Paulo, v. 9, n.16, julho/dezembro 1997. Disponível em: <http://www.eac.fea.usp.br/>. Acesso em: 07 Set. 2008.

SILVA, Antônio Rogério da. Psicologia Contemporânea. Análise de Texto: SKINNER, B. F. Sobre o Behaviorismo; caps. 1 e 13, p. 13-22 e 177-185. Disponível em: < http://www.geocities.com/discursus/textos/bskinner.html> Acesso em: fev. 2009. 
SILVA, Tânia Moura da; SPERONI, Valdemar. Os princípios éticos e a ética profissional. Revista Brasileira de Contabilidade, Brasília, DF. Conselho Federal de Contabilidade, ano 27, n 113 , p. 77-79, set/out.1998.

SKINNER, Burrhus Frederic. Questões recentes na analise comportamental. Tradução da 2. ed. Por Anita Liberalesso. Campinas, São Paulo: Papirus, 1995

SKINNER, Burrhus Frederic. Sobre o Behavorismo. Tradução de Maria da Penha Villalobos. São Paulo: Cultrix, 1999. 